CASE REPORT

\title{
Schamberg's disease in a case of severe obstructive sleep apnea: A case report
}

\section{S. Ramnathan lyer*, Revati R. lyer, R.B. Sonavdekar}

1. Consultant Physician and Consultant Sleep Medicine, Ambika Clinic, A/224,Kasturi Plaza, Manpada Road Dombivli, East. Dist.Thane

2. Consultant Gynaecologist and Obstetrician,Ambika Clinic, A/224,Kasturi Plaza, Manpada Road, Dombivli East. Dist.Thane

3. Consultant Dermatologist,Kasturi Plaza, Manpada Road, Dombivli, East. Dist.Thane

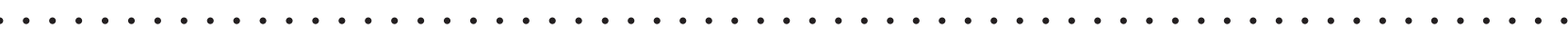

DOI No: 10.5958/0974-0155.2015.00006.6

Indian J Sleep Med 2014; 9.4, 183-185

\begin{abstract}
The present case refers to a patient who had complaints of loud snoring, excessive daytime sleepiness with skin lesions in legs and feet and uncomfortable itchy sensation in eyes. The skin lesions were compatible with a diagnosis of Schamberg's disease and the ophthalmic complaints were possibly a variant of floppy eyelid syndrome. Application of overnight bilevel positive airway pressure therapy resulted in dramatic improvement in the ophthalmic complaints. Further on after regular use of bilevel positive airway pressure therapy no new capillary hemorrhages were observed.
\end{abstract}

Keywords: Schamberg's disease, Obstructive sleep apnea, Bilevel positive airway pressure therapy.

\section{Introduction}

$\bigcup_{\mathrm{I} t}^{\mathrm{d}}$ leep-disordered breathing(SDB) is a common disorder but not well recognized in clinical practice.

It consists of a spectrum of disorders, namely snoring, upper airway resistance syndrome, obstructive sleep apnea-hypopnea syndrome(OSAHS), and obesity hypoventilation syndrome. Snoring is common among general population. Overall, snoring is reported to affect $19 \%-37 \%$ general population and more than $50 \%$ middle-aged men ${ }^{1}$. The prevalence of OSAHS has been reported to be $24 \%$ among men and $9 \%$ among women ${ }^{2}$. In the United States, the prevalence of OSAHS is 3\%$7 \%$ among adult men and $2 \%-5 \%$ among adult women ${ }^{3}$.

\section{Address for correspondence}

\section{Dr. S. Ramnathan lyer}

303, Shree Dhanashree CHS Ltd.

A Wing Veer Savarkar Road, Dombivli (East)

Dist. Thane 421 201, Maharashtra, India

E-mail: sramiyer@gmail.com (S. Ramnathan lyer)
In India, Udwadia et al. ${ }^{4}$ reported habitual snoring in $26 \%$ of the study population (middle-aged urban Indian men) and the estimated prevalence of SDB was $19.5 \%$ and that of OSAHS (SDB with daytime hypersomnolence) was $7.5 \%$. Sharma et al. ${ }^{5}$ reported the prevalence of obstructive sleep apnea (OSA) as $13.74 \%$ in habitual snorers and $3.57 \%$ in non-habitual snorers. OSAHS has several consequences, chiefly cardiometabolic, ${ }^{6}$ which places it under the watchful eye of the physician. The presentation of the disorder can be classical such as loud snoring coupled with excessive daytime sleepiness and also atypical, where snoring is ignored and daytime sleepiness is overcome by tobacco/ tea/coffee consumption. Patients often present with cardiometabolic consequences that assume importance while sleep complaints are often relegated to a level of secondary importance.

Dermatological consequences of OSAHS have not been reported in literature. The present case had obvious skin problems that could be attributed to OSAHS. Floppy 
eyelid syndrome (FES) is known to be associated with OSAHS ${ }^{7}$. However, several patients can have a milder variant that can be a part of unrefreshed sleep and prolonged sleep inertia.

\section{Case report}

A 56-year-old man presented to the first author with loud snoring and excessive daytime sleepiness since 6-8 months. There was history of snoring along with gradual increase in body weight. The other complaints were cough off and on since 15 days, discoloration of skin in both legs and feet, and uncomfortable feeling and itching in both eyes, more on awakening. The ophthalmic complaint was troublesome because it affected the daytime sleepiness. Several ophthalmic consultations were of no avail. Sleep history showed sleep times at around 10.30 $\mathrm{pm}$ with immediate sleep onset,very loud habitual snoring, nocturia 2-5 times, sleep talking, jerking in sleep, drooling, and hyperacidity coupled with drinking water at night. The Epworth sleepiness scale score measured $>15$. Personal history included smoking 4-5 cigarettes/day coupled with fair amount of alcohol consumption. Increased appetite with fast eating was prominent in sleep history. There was no history of diabetes, hypertension, ischemic heart disease, and drug/ food allergy. The positive clinical findings were as follows: height, $168 \mathrm{~cm}$; body weight, $112 \mathrm{~kg}$; body mass index, $39.6 \mathrm{~kg} / \mathrm{m}^{2}$; puffy face; macroglossia; crowded pharynx; congested throat; pulse rate, $96 / \mathrm{min}$ regular; and blood pressure, 150/80 $\mathrm{mmHg}$. Examination of legs showed irregular patches of orange and brownish pigmentation of both legs. The lesions were macular. The opinion of dermatologists was sought who diagnosed the case as Schamberg's disease. There was also pitting edema in both legs (Figure $1 \& 2$ ). Examination of cardiovascular and respiratory systems was normal. There was no clinical evidence of heart failure. Abdomen showed 2-cm nontender hepatomegaly in midclavicular line. Patient was hospitalized. The ECG showed right atrial hypertrophy whereas the $2 \mathrm{D}$ echocardiography showed moderate concentric left ventricular (LV) hypertrophy and LV diastolic dysfunction. Pulmonary function test was suggestive of mild restriction with good reversibility whereas sonological examination of abdomen showed hepatomegaly with fatty liver.

Technician-attended polysomnography(PSG) was performed using ALICE 5, which showed respiratory disturbance index (RDI) of 65.2 per hour with lowest
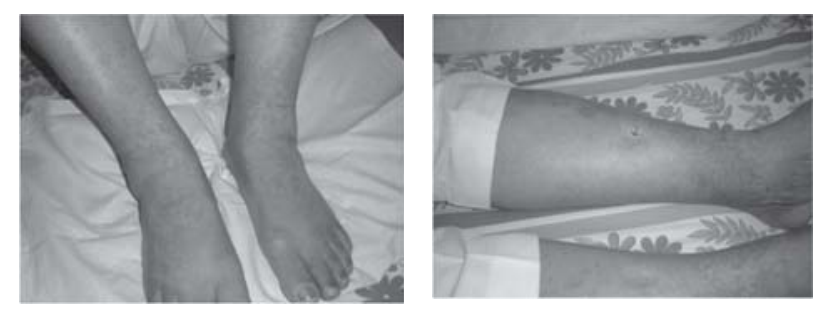

Figure $1 \& 2$ : Photographs showing irregular plaques of orange pigmentation (characteristic of Schamberg's Purpura) and edema in both legs

oxygen desaturation of 52\% (PSG suggestive of severe OSAHS). The rapid eye moment (REM) sleep was $8.7 \%$. Daytime arterial blood gases in awake state showed $\mathrm{PCO}_{2}$ of $53 \mathrm{mmHg}$ and $\mathrm{PO}_{2}$ level of $58 \mathrm{mmHg}$. Patient was titrated with bilevel positive airway pressure (BiPAP) the following night and inspiratory positive airway pressure of $12 \mathrm{~cm} \mathrm{H} \mathrm{H}_{2} \mathrm{O}$ and expiratory positive airway pressure of $6 \mathrm{cmH}_{2} \mathrm{O}$ were estimated. The resultant RDI was 1.1 per hour and lowest oxygen saturation was $91 \%$. The REM sleep was increased to $21.5 \%$. A remarkable improvement was observed in patient's general condition including ophthalmic complaints after the first night therapy with BiPAP. Patient was advised to continue use of BiPAP while sleeping and is being closely followed up every 6 months. The effects of BiPAP were reflected clinically in the form daytime alertness and decreased craving for food, with normal speed of eating. No fresh skin lesions were observed and also edema of feet and legs disappeared. A sense of general well-being was reported by the patient.

\section{Discussion}

The authors have presented a case of severe OSAHS having two consequences that are not reported in literature. The first is Schamberg's disease also known as progressive pigmented purpuric dermatosis. Schamberg first described it in $1901^{8}$. Subsequently he reported three cases ${ }^{9}$. The skin lesions described in this case are characteristic of Schamberg's disease. The disease is known to occur more in males occurring at any age from childhood onwards. The lesions occur most frequently in the lower limbs but may occur anywhere in the body including hands. The lesions have been described as irregular plaques of orange or brown pigmentation due to hemosiderin with characteristic "cayenne pepper spots" appearing within and at the edge of old lesions.Venous insufficiency often contributes to the localization of skin lesions. It is well known that 
normal respiration coupled with competent venous valves and muscle contractions in legs is necessary for proper cephalad venous blood flow. In OSAHS, there is intermittent respiratory arrest affecting the venous blood flow. Also, the mechanical obstruction creates a stress in the venous wall resulting in leaking blood vessels and capillaritis near the surface of the skin. This allows the red blood cells to slip through into the skin. The red blood cells in the skin then fall apart and release their iron that gives the characteristic rust color to the lesions. The bilateral nature of the disease points to a systemic cause. Baden ${ }^{10}$ reported that the disease has a familial incidence. It must be appreciated that OSAHS can run in families due to anatomical reasons.

The second consequence was the uncomfortable itchy feeling in eyes. Recently, $\mathrm{McNabb}^{7}$ has reported association of OSA with several eye disorders, namely FES, anterior ischemic optic neuropathy, optic neuropathy, glaucoma, and papilledema secondary to raised intracranial pressure. Woog ${ }^{11}$ reported three cases of FES with OSA. The present patient did not have the classical presentation of FES but can be described as having its variant. The remarkable reversal of ophthalmic symptoms following the use of BiPAP indicates that restoration of sleep architecture coupled with stabilization of respiration was responsible for the favorable outcome.

\section{Conclusion}

SDB has several consequences of which cardiometabolic are life threatening. It is important to recognize SDB in clinical practice. Facial abnormalities that are conducive for development of OSAHS are well known. Presence of Schamberg's disease should raise the suspicion of SDB. This further fortifies the fact that skin is often the mirror of internal disease. Patients who have eye disorders such as FES, optic neuropathy, glaucoma, papilledema, and raised intracranial tension need to be screened for underlying SDB. It would be worthwhile to look at the legs and face of a suspected case of SDB.

\section{Acknowledgements}

We thank Mr. Sachin Navre (Sleep Technologist), Mr. S.V. Iyer, Smt. Vijayalakshmi V. Iyer, Mr. R. Venkatraman, Dr. Bhagyalakshmi Venkatraman, Minakshi R., and Manasvisai for their help.

\section{References}

1. Lugaresi F, Cirignotta F, Coccagna G, Piana C. Some epidemiological data on snoring and cardiocirculatory disturbances. Sleep 1980;3: 221-4.

2. Young T, Palta M,Dempsey J,Skatrud J, Weber S, Badr S.The occurrence of sleep disordered breathing among middle aged adults. N Engl J Med 1993;328:1230-5.

3. Punjabi NM. The epidemiology of adult obstructive sleep apnea. ProcAm Thorac Soc 2008;5(2):136-43.

4. Udwadia ZF, Doshi AV,Lonkar SG, Singh CI.Prevalence of sleep disordered breathing and sleep apnea in middle aged urban Indian men. Am J Respir Crit Care Med 2004; 169:167-73.

5. Sharma SK, Kumpawat S,Banga A, Goel A.Prevalence and risk factors of obstructive sleep apnea syndrome in a population of Delhi,India. Chest2006;130(1):149-58.

6. Iyer SR. Sleep and type 2 diabetes mellitus-clinical implications. J Assoc Physicians India 2012;60:42-7.

7. McNabb AA. The eye and sleep.Clin Experiment Ophthalmol 2005;33:117-25.

8. Schamberb JF. A peculiar progressive pigmentary disease of the skin.Br J Dermatol 1901;13:1-5(quoted in the Textbook of Dermatology-Dowd PU,Champion RH.Purpura, 6th edn., Vol. 3, Champion RH, Burton JL, Burns DA, Breathnach SM(Eds.). Blackwell Science Oxford, 1998).

9. Schamberb JF. Report of 3 cases of progressive pigmentary dermatosis with particular reference to the blood cholesterol.Br J Dermatol 1927;39:389-93(quoted in the Textbook of Dermatology-Dowd PU,Champion RH.Purpura, 6th edn., Vol. 3. Champion RH,Burton JL,Burns DA, Breathnach SM (Eds.). Blackwell Science Oxford, 1998).

10. Baden HP. Familial Schamberg's disease. Arch Dermatol 1964;90:400.

11. Woog JJ. Obstructive sleep apnea and the floppy eyelid syndrome. Am J Ophthalmol1990;110:314-34. 